\title{
Blood pressure and haemodynamics in teenagers
}

\author{
ALBERT HOFMAN, R CURTIS ELLISON, JANE NEWBURGER, OLLI S MIETTINEN \\ From the Department of Epidemiology, Harvard School of Public Health; Division of Preventive Cardiology, \\ Department of Cardiology, The Children's Hospital Medical Center; Department of Pediatrics, Harvard Medical \\ School; Boston, Massachusetts, USA
}

SUMMARY It has been suggested that a hyperkinetic circulatory state, with high cardiac output, causes high blood pressure in childhood and, secondarily, in adulthood. We studied blood pressure and cardiac output in 319 subjects aged 15 to 19 . Blood pressure was measured with an automated device; cardiac output was estimated by $M$-mode echocardiography and indexed by body surface area. The distribution of cardiac output was stratified using quartiles. Mean arterial pressure was virtually constant over these strata, with boys and girls showing essentially the same pattern. Linear regression of mean arterial pressure on cardiac output yielded a coefficient which was not significantly different from zero. A history of high blood pressure in the parents was positively associated with mean arterial pressure, but unrelated to cardiac output, in the offspring. This evidence does not support the hypothesis that the hyperkinetic circulatory state causes high blood pressure in childhood; rather, raised blood pressure in adolescents appears to relate to increased peripheral vascular resistance. Therefore, our findings lend support to the view that change in blood pressure over time is caused by a gradual increase in peripheral resistance beginning early in life.

It has been proposed that a "hyperkinetic" circulatory state $^{1}$ during youth, characterised by a high cardiac output, plays a part in the aetiology of high blood pressure. ${ }^{2}$ Many children and adolescents with high blood pressure, sometimes referred to as "labile" or "borderline" hypertensives, are thought to have high cardiac output. ${ }^{3}$ It has been suggested that an early rise in blood pressure, whether resulting from increased cardiac output or from other factors, causes alterations in the vascular wall ${ }^{4}$ and/or the kidneys. ${ }^{5}$ These alterations are held to be responsible for the increased peripheral resistance which accompanies high blood pressure in adults. ${ }^{6}$

To test whether a hyperkinetic circulatory state is a determinant of high blood pressure in the young, we examined blood pressure in relation to cardiac output in 319 subjects aged 15 to 19.

\section{Subjects and methods}

The subjects were participants of the Collaborative Perinatal Study, ${ }^{7}$ in which pregnant women and those of their children born between 1959 and 1966 were studied in 12 medical centres in the USA. Eligible for the present study were white members of the Boston cohort of the Perinatal Study, born between 1959 and 1962 , who had no known congenital anomalies and who had been re-examined as part of the Perinatal Study at 7 years of age. A sample of about 900 persons, unselected as to blood pressure, was invited by letter to take part in a study of cardiovascular risk indicators $8 ; 456$ persons responded and 380 were examined. This report deals with subjects who were 15.0 to 19.9 years of age at the time of the cardiovascular study (1977 to 1979). There were a total of 319 (168 male and 151 female) subjects. The majority (215) were 17 years of age.

Systolic and diastolic blood pressures were measured with a Narco Physiograph automated device as described earlier. ${ }^{8}$ Diastolic pressure was based on the fifth phase of the Korotkoff sounds. The measurements were obtained between 8.00 and $9.30 \mathrm{am}$, with the subjects in a fasting state. All the readings were obtained with appropriately sized cuffs ${ }^{9}$ and with the subjects in a recumbent position. Mean arterial pressure was computed by adding one third of the pulse pressure to diastolic pressure. A history of high blood pressure was obtained from the parents by interview.

Cardiac output was obtained by M-mode echocardiography, as described by Roelandt, ${ }^{10}$ on the same occasion as when blood pressure was measured. Stroke volume was estimated by subtracting the cubed end- 
systolic diameter of the left ventricle from the cubed end-diastolic diameter. Heart rate was measured from the echocardiogram. An index of cardiac output was obtained by dividing it by body surface area, calculated according to Dubois and Dubois. ${ }^{11}$

The relation between cardiac output (index) and blood pressure was analysed in three ways. Firstly, we compared mean levels of mean arterial pressure among strata based on quartiles of cardiac output. Secondly, cardiac output of subjects with the highest values of mean arterial pressure was compared with that in the other study subjects. Thirdly, a linear regression analysis of mean arterial pressure on cardiac output was made. No age stratification or standardisation was applied because of the narrowness of the range of age.

\section{Results}

The values of mean arterial pressure ranged from 61 to $107 \mathrm{mmHg}$, with an average of 83.0 . The average was higher for boys than for girls, because of a higher average systolic pressure. Mean cardiac output (index) was $3 \cdot 15 \mathrm{l} / \mathrm{min}$ per $\mathrm{m}^{2}$, with similar values for male and female subjects (Table 1 ).

Mean values of mean arterial pressure were virtually constant over the strata of cardiac output. Boys and girls showed essentially the same pattern (Table 2).

The subjects with the highest values of mean arterial pressure (90th centile or higher) had a mean cardiac output of $3.30 \mathrm{l} / \mathrm{min}$ per $\mathrm{m}^{2}$ (95\% CI: 3.01 to 3.59 ), whereas those with mean arterial pressure less than the 90 th centile had a mean cardiac output of $3 \cdot 14(95 \% \mathrm{CI}$ :

Table 1 Blood pressure, heart rate, and cardiac output in subjects aged 15 to 19

\begin{tabular}{lrr}
\hline & $\begin{array}{l}\text { Boys } \\
\text { Mean } \pm S D \\
(n=168)\end{array}$ & $\begin{array}{l}\text { Girls } \\
\text { Mean } \pm S D \\
(n=151)\end{array}$ \\
\hline Systolic blood pressure $(\mathrm{mmHg})$ & $127.7 \pm 11.6$ & $117.4 \pm 10.7$ \\
Diastolic blood pressure $(\mathrm{mmHg})$ & $64.4 \pm 9.2$ & $63.9 \pm 8.9$ \\
Mean arterial pressure $(\mathrm{mmHg})$ & $84.2 \pm 8 \cdot 2$ & $81.7 \pm 8.3$ \\
Heart rate $($ beats/min) & $61.5 \pm 11 \cdot 1$ & $70 \cdot 1 \pm 12.7$ \\
Cardiac output $\left(1 / \mathrm{min}\right.$ per $\left.\mathrm{m}^{2}\right)$ & $3.2 \pm 0.78$ & $3.11 \pm 0.82$ \\
\hline
\end{tabular}

3.05 to $3 \cdot 23)$. The difference between these means was not significantly different from zero.

Linear regression of mean arterial pressure on cardiac output yielded a coefficient of $0.6 \mathrm{mmHg} / 1$ per min per $\mathrm{m}^{2}(95 \% \mathrm{CI}:-0.6$ to 1.8$)$, which also was not significantly different from zero.

\section{Discussion}

Our finding of no association between blood pressure and cardiac output in teenagers is at variance with previous studies 2312 in which cardiac output was measured invasively. Recent investigations, ${ }^{13}{ }^{14}$ using non-invasive (echocardiographic) estimation of cardiac output, failed to show high cardiac output in children with relatively high blood pressure. In those studies the number of subjects was relatively small and "hypertensive" children were contrasted with normotensive controls. In the present study cardiac output was estimated in a study population unrestricted as to blood pressure, enabling evaluation of the trend of blood pressure over the whole range of cardiac output, with avoidance of the potential bias caused by varying familiarity of cases and controls with the procedures.

The study population comprised newborns enrolled in a large perinatal study ${ }^{7}$ who were re-examined at age 7. An unselected sample was invited for the present study and in about $40 \%$ of the invited subjects both blood pressure and cardiac output were measured. No appreciable differences in blood pressure, heart rate, height, and weight at the age of 7 were found between those who took part in the present study and those who did not. Therefore, it seems unlikely that the procedure of subject selection has led to differential exclusion of teenagers with high blood pressure and high cardiac output.

The non-invasive measurement of cardiac output may be subject to criticism..$^{15} 16$ Though the measurement of cardiac output by echocardiography undoubtedly involves considerable random errors, this also is true when invasive techniques are employed. Nevertheless, stroke volume values obtained by angiocardiography and $\mathrm{M}$-mode echocardiography have

Table 2 Mean arterial pressure (mean \pm 1 SEM) by categories of cardiac output

\begin{tabular}{|c|c|c|c|c|c|c|c|}
\hline \multicolumn{2}{|c|}{ Cardiac output } & \multicolumn{6}{|c|}{ Mean arterial pressure $(\mathrm{mmHg})$} \\
\hline \multirow[t]{2}{*}{ Stratum } & \multirow{2}{*}{$\begin{array}{l}\text { Range } \\
\left(1 / \text { min per } m^{2}\right)\end{array}$} & \multicolumn{2}{|c|}{ Both sexes } & \multicolumn{2}{|l|}{ Boys } & \multicolumn{2}{|l|}{ Girls } \\
\hline & & No. & Mean $\pm S E M$ & No. & Mean $\pm S E M$ & No. & $M e a n \pm S E M$ \\
\hline $\begin{array}{l}\text { I } \\
\text { II } \\
\text { III } \\
\text { IV } \\
\text { All strata }\end{array}$ & $\begin{array}{l}(1 \cdot 6-2 \cdot 5) \\
(2 \cdot 6-3 \cdot 0) \\
(3 \cdot 1-3 \cdot 6) \\
(3 \cdot 7-5 \cdot 5) \\
(1 \cdot 6-5 \cdot 5)\end{array}$ & $\begin{array}{r}79 \\
80 \\
80 \\
80 \\
319\end{array}$ & $\begin{array}{l}82 \cdot 8 \pm 0 \cdot 9 \\
82 \cdot 3 \pm 1 \cdot 1 \\
82 \cdot 9 \pm 0 \cdot 9 \\
84 \cdot 2 \pm 1 \cdot 0 \\
83 \cdot 1 \pm 0 \cdot 5\end{array}$ & $\begin{array}{r}42 \\
42 \\
42 \\
42 \\
168\end{array}$ & $\begin{array}{l}85 \cdot 2 \pm 1 \cdot 1 \\
83 \cdot 9 \pm 1 \cdot 4 \\
83 \cdot 5 \pm 1 \cdot 2 \\
84 \cdot 3 \pm 1 \cdot 4 \\
84 \cdot 2 \pm 0 \cdot 6\end{array}$ & $\begin{array}{r}37 \\
38 \\
38 \\
38 \\
151\end{array}$ & $\begin{array}{l}82.4 \pm 1.4 \\
79.4 \pm 1 \cdot 4 \\
81 \cdot 5 \pm 1 \cdot 3 \\
83.6 \pm 1.4 \\
81.7 \pm 0.7\end{array}$ \\
\hline
\end{tabular}

^Ranges for boys and girls separately were only slightly different from the ranges for boys and girls combined. 
been shown to be in reasonably good agreement in adults ${ }^{17}$ and children. ${ }^{18} \mathrm{We}$ used the cube method to calculate stroke volume ${ }^{10}$; application of the corrected cube method as suggested by Teichholz et al. ${ }^{17}$ did not alter the observed regression coefficient between blood pressure and cardiac output. Though random errors in cardiac output tend to lead to an underestimate of the true relation with blood pressure, we believe that these errors are unlikely to be much larger in our study than in previous ones, in which cardiac output was measured invasively. We therefore think it improbable that information bias is responsible for our findings.

Epidemiological studies ${ }^{19}$ have shown that levels of blood pressure in young people have good predictive value for later life. This "tracking" of blood pressure implies that the study subjects with the highest mean arterial pressure are likely to be future hypertensives. We found no difference between their average cardiac output and that of their counterparts with lower mean arterial pressure and this is in agreement with the finding of no association between levels of blood pressure and of cardiac output over the whole range of the latter.

Our study indicates that in adolescents a high blood pressure reflects high resistance of the vascular bed rather than high cardiac output. As there is evidence for high blood pressure to run in families, ${ }^{20}$ one would expect high blood pressure in parents to be associated with high vascular resistance, and not with high cardiac output, in the offspring. The Fig. shows that this was the case in our subjects: children whose parents had a history of high blood pressure had higher mean arterial pressure and vascular resistance than children with no parental history of high blood pressure (Table 3 ).

The evidence presented here suggests that the hyperkinetic circulatory state does not have an important role in the aetiology of high blood pressure, since blood pressure in teenagers seems to be related to peripheral resistance, rather than to cardiac output. These results support the view that rises in blood pressure as people get older are caused by a gradual increase in peripheral resistance, which begins quite

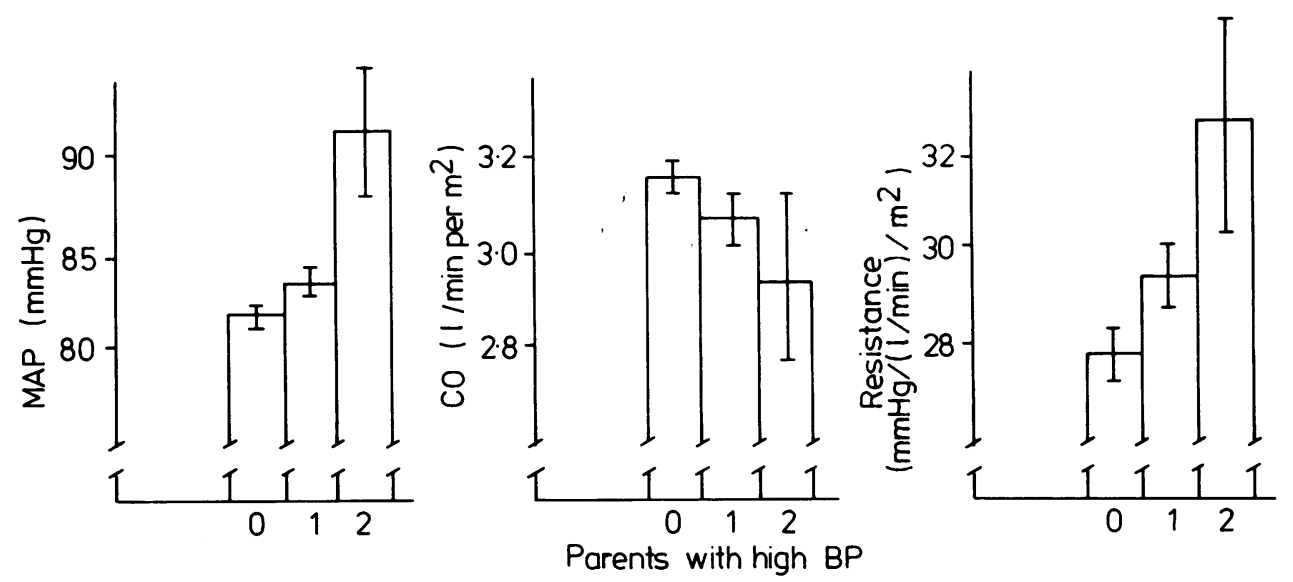

Fig. Mean arterial blood pressure, cardiac output, and total peripheral resistance in teenagers, according to number of parents with a history of high blood pressure. Mean values are given with 1 SEM.

Table 3 Mean arterial pressure $(\mathrm{mmHg})$, cardiac output (l/min per $\left.\mathrm{m}^{2}\right)$, and vascular resistance $\left(\operatorname{mmHg} / \mathrm{l}\right.$ per min per $\left.\mathrm{m}^{2}\right)$ in teenagers, according to history of high blood pressure in their parents

\begin{tabular}{|c|c|c|c|c|}
\hline \multirow[t]{2}{*}{$\begin{array}{l}\text { History of high } \\
\text { blood pressure }\end{array}$} & \multirow[t]{2}{*}{ No. } & \multirow{2}{*}{$\frac{\begin{array}{l}\text { Mean arterial } \\
\text { pressure }\end{array}}{\text { Mean } \pm S E M}$} & \multirow{2}{*}{$\begin{array}{l}\text { Cardiac output } \\
\text { Mean } \pm S E M\end{array}$} & \multirow{2}{*}{$\begin{array}{l}\text { Resistance }^{\star} \\
\text { Mean } \pm S E M\end{array}$} \\
\hline & & & & \\
\hline $\begin{array}{l}\text { Neither parent } \\
\text { One parent } \\
\text { Both parents } \\
\text { Regression coefficient }{ }^{\star \star} \\
\left(\mathbf{P}_{(2)} \text {-value }\right)^{\star \star \star}\end{array}$ & $\begin{array}{r}182 \\
80 \\
11\end{array}$ & $\begin{array}{l}82 \cdot 1 \pm 0.6 \\
84 \cdot 3 \pm 1 \cdot 0 \\
90 \cdot 2 \pm 3 \cdot 1 \\
2.9 \pm 0.9 \\
(0.003)\end{array}$ & $\begin{array}{l}3.17 \pm 0.06 \\
3.07 \pm 0.09 \\
2.91 \pm 0.28 \\
-0.11 \pm 0.09 \\
(0.19)\end{array}$ & $\begin{array}{l}27 \cdot 7 \pm 0.5 \\
28 \cdot 8 \pm 0 \cdot 8 \\
32 \cdot 3 \pm 2 \cdot 5 \\
1.5 \pm 0.8 \\
(0.06)\end{array}$ \\
\hline
\end{tabular}

^Computed as: resistance $=$ mean arterial pressure $/$ cardiac output.

$\star \star$ Trend of mean pressure, cardiac output, and resistance on history of high blood pressure in parents; coefficient obtained by weighted regression analysis, using the inverse of the variances as weights.

$\star \star \star$ Two-sided $p$ value, computed using $\chi^{2}$ test, $1 \mathrm{df}$, to test difference from zero. 
early in life.

This research was supported by grants from the National Heart, Lung and Blood Institute. Dr Hofman was supported by a grant from the Netherlands Organisation for Pure Scientific Research ZWO, while he was a research fellow in the Department of Epidemiology of the Harvard School of Public Health.

\section{References}

1 Gorlin R. The hyperkinetic heart syndrome. FAMA 1962; 182: 823-9.

2 Widimský J, Fejtarová MH, Fejfar Z. Changes of cardiac output in hypertensive disease. Cardiologia 1957; 31:3819.

3 Tarazi RC, Dustan HP. The hemodynamics of labile hypertension in adolescents. In: Strauss J, ed. Pediatric nephrology. New York: Plenum Press, 1976: 97-108.

4 Folkow B. The haemodynamic consequences of adaptive structural changes of the resistance vessels in hypertension. Clin Sci 1971; 41: 1-12.

5 Brown JJ, Lever AF, Robertson JIS, Schalekamp MA. Pathogenesis of essential hypertension. Lancet 1976; i: 1217-9.

6 Frohlich ED, Tarazi RC, Dustan HP. Re-examination of the hemodynamics of hypertension. Am J Med Sci 1969; 257: 9-23.

7 Niswander KR, Gordon M. The women and their pregnancies. Philadelphia: WB Saunders, 1972.

8 Ellison RC, Sosenko JM, Harper GP, Gibbons L, Pratter FE, Miettinen OS. Obesity, sodium intake, and blood pressure in adolescents. Hypertension 1980; 2, suppl 1: 78-82.

9 Recommendations of the task force on blood pressure control in children. Pediatrics 1977; 59, suppl: 797-820.
10 Roelandt J. Practical echocardiography. Rotterdam: Rotterdam University Press, 1975.

11 Dubois D, Dubois EF. Clinical calorimetry XII. A formula to estimate the approximate surface area if height and weight be known. Arch Intern Med 1916; 17: 863-76.

12 Lund-Johansen P. Hemodynamics in early essential hypertension. Bergen: Thesis, 1967.

13 Goldring D, Hernandez A, Choi S, et al. Blood pressure of a high school population. II. Clinical profile of the juvenile hypertensive. F Pediatr 1979; 95: 298-304.

14 Hofman A, Roelandt JTRC, Boomsma F, Schalekamp MADH, Valkenburg HA. Haemodynamics, plasma noradrenaline and plasma renin in hypertensive and normotensive teenagers. Clin Sci 1981; 61: 169-74.

15 Linhart JW, Mintz GS, Segal BL, Kawai N, Kotler MN. Left ventricular volume measurement by echocardiography: fact or fiction? Am $\mathcal{F}$ Cardiol 1975; 36: 114-8.

16 Feigenbaum $\mathrm{H}$. Echocardiographic examination of the left ventricle (Editorial). Circulation 1975; 51: 1-7.

17 Teichholz LE, Kreulen T, Herman MV, Gorlin R. Problems in echocardiographic volume determinations: echocardiographic-angiographic correlations in the presence or absence of asynergy. Am $\mathcal{F}$ Cardiol 1976; 37: $7-11$.

18 Silverman NH, Ports TA, Snider AR, Schiller NB, Carlsson E, Heilbron DC. Determination of left ventricular volume in children: echocardiographic and angiographic comparisons. Circulation 1980; 62: 548-57.

19 Szklo M. Epidemiologic patterns of blood pressure in children. Epidemiol Rev 1979; 1: 143-69.

20 Zinner SH, Levy PS, Kass EH. Familial aggregation of blood pressure in childhood. $N$ Engl F Med 1971; 284: $401-4$.

Requests for reprints to Dr A Hofman, Department of Epidemiology, Erasmus University, PO Box 1738, 3000 DR Rotterdam, The Netherlands. 